International JOURNAL OF MULtidisciplinaRy Research AND ANALysis

ISSN[Online] : 2643-9875 || ISSN[Print] : 2643-9840

Volume 3 Issue 09 September 2020

DOI: 10.47191/ijmra/v3-i9-11, Impact Factor : 5.522

Page No: $126-133$

\title{
Knowledge, Attitude and practice against the 2019 Novel Coronavirus (COVID-19) Among the Jahrom city people: A Cross-Sectional Study
}

\author{
Navid Kalani ${ }^{1}$, Seyed Ebrahim Sadeghi ${ }^{2}$, Naser Hatami ${ }^{3}$, Mohammad Zarenezhad ${ }^{4}$, Farshid Javdani ${ }^{2}$, \\ Mohammad Rahmanian ${ }^{5 *}$
}

1. Research center for social Determinants of Health, Jahrom University of Medical Sciences, Jahrom, Iran.

2. Department of Anesthesiology, Shiraz University of Medical Sciences, Shiraz, Iran,

3. Student Research Committee, Jahrom University of Medical Sciences, Jahrom, Iran.

4. Iranian legal medicine research center, Legal medicine organization, Tehran, Iran.

5. Anesthesiology, Critical care and pain management research center, Jahrom University of Medical Sciences, Jahrom, Iran.

\section{Corresponding Author: Dr Mohammad Rahmanian. Anesthesiology,}

Critical care and pain management research center, Jahrom University of Medical Sciences, Jahrom, Iran.

\section{ABSTRACT: \\ BACKGROUND:}

A new infectious disease named Coronavirus disease (COVID-19) emerged at the end of 2019 and is rapidly spreading across the globe. Most of the instructions provided to stop this outbreak are based on personal behavior and Social Distancing. So people need to be aware of the illness and behavior that they present in the course of the Coronavirus outbreak. The purpose of this study was to investigate the attitude, awareness, and preventive behaviors of people in Jahrom, southern Iran.

\section{METHOD:}

In this descriptive cross-sectional study, 1570 people of Jahrom city were surveyed about COVID-19 by designing a questionnaire consisting of areas of knowledge, attitude, and practice of people. Also, the source of their information about coronavirus and the amount of trust in media were investigated. After confirming the validity and reliability of the questionnaire in a pilot study, sampling was done by an online survey. The online questionnaire was completed by individuals and the results were analyzed by SPSS v. 21 analyzed.

\section{RESULTS:}

The study involved 1570 Jahrom citizens, $57.6 \%$ of whom were female and the rest were male. The mean score of knowledge, attitude, and practice of people in Jahrom city was above average. Trust in the media was at an average level (49.18\%). The multiple linear regression of demographic variables revealed the significant inverse effect of the male gender and number of households on awareness; while age, education level and marital status had a positive effect predicting awareness level ( $p=$ $0.001, F=28.057)$. Regarding the attitude variable, there was a reverse effect of the male gender and the direct effect of age and level of education $(p=0.001, F=6.78)$. In the study of practice, the inverse effect of the male gender was observed $(p=$ $0.002, \mathrm{~F}=3.30)$.

\section{CONCLUSION:}

Given the importance of community-based individual behavior in controlling the COVID-19 outbreak, providing a tool for measuring the knowledge, attitude, and practice of the community, the questionnaire designed in this study can be used in future research. Also, this study revealed that men and young people appear to have poorer knowledge, attitudes, and practice. KEY WORDS:

Knowledge, Attitude, practice, Coronavirus, COVID-19 


\section{Knowledge, Attitude and practice against the 2019 Novel Coronavirus(COVID-19) Among the Jahrom city people:}

\section{A Cross-Sectional Study}

\section{INTRODUCTION:}

A large family of coronaviruses is known to cause mild common colds and also outbreaks of severe acute respiratory syndrome (SARS) diseases (1). In December 2019, for the first time in Wuhan City, China, a new type of coronavirus has been identified with an outbreak of people experiencing severe acute respiratory syndrome for no apparent reason and treatments were not effective (2). With an increase of the mortality to more than 1,000 people, the World Health Organization gave an official name to the disease, COVID-19, referring to "corona," "virus," "disease," and 2019 (3). Since February 19, 2020, this new coronavirus killed more than 2709 people and more than 73332 people get infected in 80 countries, including Thailand, South Korea, Japan, Taiwan, Australia, Singapore, Nepal, Vietnam, Indonesia, Germany, Russia, Fiji, France, Iran and the US (4). Human-to-human transmission of the virus has been confirmed in virology studies. Coronaviruses are spread primarily by close contact, especially through coughs and sneezing respiratory droplets been thrown up to 3 meters (5). Virus RNA has also been found in stool samples from infected patients (5). The new coronavirus appears to be less dangerous than last SARS outbreaks, and it has been to cause severe symptoms in 15 to 20 percent of cases. Coronavirus can be found in the surrounding environment and can be transmitted through contact with door handles, beds, buttons, desks, and other metal and plastic surfaces that are in direct contact with an infected person (5). Studies suggest that coronaviruses can persist on different surfaces for an average of four to five days. Some of them can also survive out of the human body for up to 9 days at room temperature (6). Due to severe pulmonary injuries in coronavirus infection, the mortality rate in infected patients and patients who require mechanical ventilation have been very high (7). Due to the lack of standard treatment and effective vaccine for the new coronavirus (8), the best way in the present situation is to avoid infection and prevent its spread. One of the primary measures in this situation is to take personal protective and hygienic measures by all community members; while people should have proper knowledge of these measures to achieve a desirable control of the outbreak. So our study aimed to evaluate Knowledge, Attitude and practice against the 2019 Novel Coronavirus (COVID-19) Among the Jahrom city people.

\section{METHODS:}

This is a descriptive cross-sectional study. The study population was Jahrom city. Jahrom city, with a surface area of 3625 square kilometers, accounts for about 3\% of the total area of Fars province in southern Iran. Sampling was done by an Electronic questionnaire via web and mobile-based applications. The study was approved by the research ethical committee of Jahrom University of medical sciences, with a code of IR.JUMS.REC.1398.122.

A questionnaire was designed to assess the Knowledge, Attitude, and Practice of the subjects. The questionnaire consisted of 24 questions about awareness, 5 of which were rated on a Likert scale with strongly disagree to strongly agree on options ranging from 0 to 4. Thirteen questions were scored on a three-point Likert scale of "Yes", "No", and "I don't know", with a score of 1 and 0 and 0 , respectively. There was 1 question about transmitting the disease that was in a four-level Likert scale form and subjects could choose more than one. When choosing options of "direct transfer when coughing" and "touching surfaces infected with the virus" and "contacting infected people (shaking, rubies, hugging)", each was given a positive score, and a negative score was given if choosing the option of consuming "infected milk and meat". There was a 5-option question for selecting high-risk groups that subjects could choose more than one option. Each of the options for "older people", "pregnant women" and "people with weakened immune systems, having the underlying disease (cancer, chronic respiratory disease, diabetes, kidney failure)" were each rated positively. While the "I don't know" option had zero scores. Diagnosis and prevention included 4 items on the three-point Likert scale: "Yes", "No", "I Don't Know". The attitude variable consisted of 17 items on the three-point Likert scale of "Yes", "No", "I Don't Know". The practice variable consisted of 12 questions out of which 11 were rated on a three-point Likert scale of "Yes", "No", "I Don't Know"; and one question about using face masks with options of "no use", "only in crowded places and communities", "most places", and "always" being scored from 0 to 3 . The coronavirus risk assessment also included 5 Likert-scale questions with very low to very high scores ranging from 1 to 5 . The source of information about disease and trust in media was also assessed by 10 questions on a Likert scale with very low to very high scores ranging from 1 to 5 . The score of knowledge, attitude, and practice of the people and the source of information and level of trust were calculated based on the sum of the questions scores and converted to percentages for a better comparison of the raw scores. Awareness scores ranged from a minimum score of 0 to 45 . Attitude ranged from 0 to 17 , practice 0 to 14 , and source of information and trust 5 to 25 . The validity of the questionnaire was confirmed by the comments of five faculty members of Jahrom University of Medical Sciences. Reliability was assessed by conducting a 40-person pilot study and Cronbach's alpha coefficient after excluding inappropriate questions for Knowledge (0.723), Attitude (0.721), Practice (0.811), Information Source (0.754), and media trust (0.728) was suitable.

Mean and the standard deviation was used to report questionnaire scores and age. Percentages of participants' scores were reported by calculating the ratio of the difference between a minimum score and the mean score to the difference of minimum 
Knowledge, Attitude and practice against the 2019 Novel Coronavirus(COVID-19) Among the Jahrom city people:

\section{A Cross-Sectional Study}

and maximum scores. The rest of the variables were expressed as numbers and percentages. Chi-square, independent $\mathrm{t}$-test and linear regression were used for data analysis in SPSS version 21.

\section{RESULTS:}

In this study, 1570 subjects from different regions of Jahrom were surveyed online. $57.6 \%$ were female and the rest were male. The majority of study participants were $31-40$ years (40.6\%) and married (74\%). $37.6 \%$ of them had a high school diploma or lower and $52.8 \%$ had a bachelor's degree or higher. $7.9 \%$ of participants were from health care staff. $61.7 \%$ lived in Townhouse and the rest in apartments. The number of households in more than half of the study participants (53.1\%) was four or more. Only $17 \%$ of subjects had traveled in the past month (Table 1 ).

Table 1. Descriptive Frequency of Demographic Variables of Study Participants

\begin{tabular}{|c|c|c|c|}
\hline & variable & $\mathrm{n}$ & $\%$ \\
\hline \multirow[t]{2}{*}{ sex } & female & 904 & 57.6 \\
\hline & male & 666 & 42.4 \\
\hline \multirow[t]{4}{*}{ age } & $18-30$ years & 491 & 31.3 \\
\hline & $31-40$ years & 637 & 40.6 \\
\hline & $41-50$ years & 293 & 18.7 \\
\hline & $51-60$ years & 149 & 9.5 \\
\hline \multirow{5}{*}{$\begin{array}{c}\text { Educationa } \\
\text { I level }\end{array}$} & Lower than diploma & 194 & 12.4 \\
\hline & Diploma & 396 & 25.2 \\
\hline & associate & 152 & 9.7 \\
\hline & Bachelor & 587 & 37.4 \\
\hline & Higher & 241 & 15.4 \\
\hline \multirow[t]{7}{*}{ occupation } & Unemployed & 317 & 20.2 \\
\hline & student & 157 & 10.0 \\
\hline & Self-employed & 305 & 19.4 \\
\hline & Health worker & 124 & 7.9 \\
\hline & employee & 43 & 2.7 \\
\hline & jobholder & 364 & 23.2 \\
\hline & others & 260 & 16.6 \\
\hline \multirow{3}{*}{$\begin{array}{l}\text { Marital } \\
\text { status }\end{array}$} & single & 385 & 24.5 \\
\hline & married & 1162 & 74.0 \\
\hline & other & 23 & 0.15 \\
\hline \multirow[t]{2}{*}{ housing } & apartment & 602 & 38.3 \\
\hline & Townhouse & 968 & 61.7 \\
\hline \multirow[t]{4}{*}{ household } & 2 & 253 & 16.1 \\
\hline & 3 & 484 & 30.8 \\
\hline & 4 & 599 & 38.2 \\
\hline & More than 5 & 234 & 14.9 \\
\hline \multirow{2}{*}{$\begin{array}{l}\text { Travel } \\
\text { history }\end{array}$} & No & 1303 & 83.0 \\
\hline & yes & 267 & 17.0 \\
\hline
\end{tabular}

The mean score of knowledge, attitude, and practice of people in Jahrom city was above average and 68.14, 78.73, 79.68\%, respectively.

Table 2. Descriptive Frequency of The mean score of knowledge, attitude, and practice of Study Participants

\begin{tabular}{|c|c|c|}
\hline \multirow{2}{*}{} & \multicolumn{2}{|c|}{ Mean score percent } \\
\cline { 2 - 3 } & $(\%)$ & STD \\
\hline Knowledge & 68.14 & 8.57 \\
\hline Attitude & 78.73 & 10.04 \\
\hline Practice & 79.68 & 11.44 \\
\hline \multicolumn{2}{|c|}{ Mean score percent was calculated based on the ratio of ((the score-minimum score)/(maximum-minimum score)) $\times 100$} \\
\hline
\end{tabular}


Knowledge, Attitude and practice against the 2019 Novel Coronavirus(COVID-19) Among the Jahrom city people:

\section{A Cross-Sectional Study}

$94.9 \%$ of study participants had heard the name of the disease and $81.5 \%$ believed that the coronavirus is contagious. Only $2 \%$ of subjects had a history of family, relatives or friend's infection to COVID-19., $87.1 \%$ and $86.6 \%$ of the people, stated the cause of COVID-19 as a virus and the appearance of COVID-19 symptoms between 3 and 14 days after exposure, respectively. Almost half of the population (52.2\%) believed that COVID-19 had no cure. $85.6 \%$ of people thought that people at higher than 50 years old are the most at risk of being exposed to coronavirus. The majority of people in Jahrom believed in measuring fever if suspected and observing suspected symptoms, and avoiding contact with suspected cases (Table 2).

The majority of people in the study believed that Fever, Cough, Sore Throat, And Body Aches were symptoms of coronary artery disease. Only $44.2 \%$ of subjects was though the Diarrhea And Constipation to be symptoms of this disease (Figure 1 ).

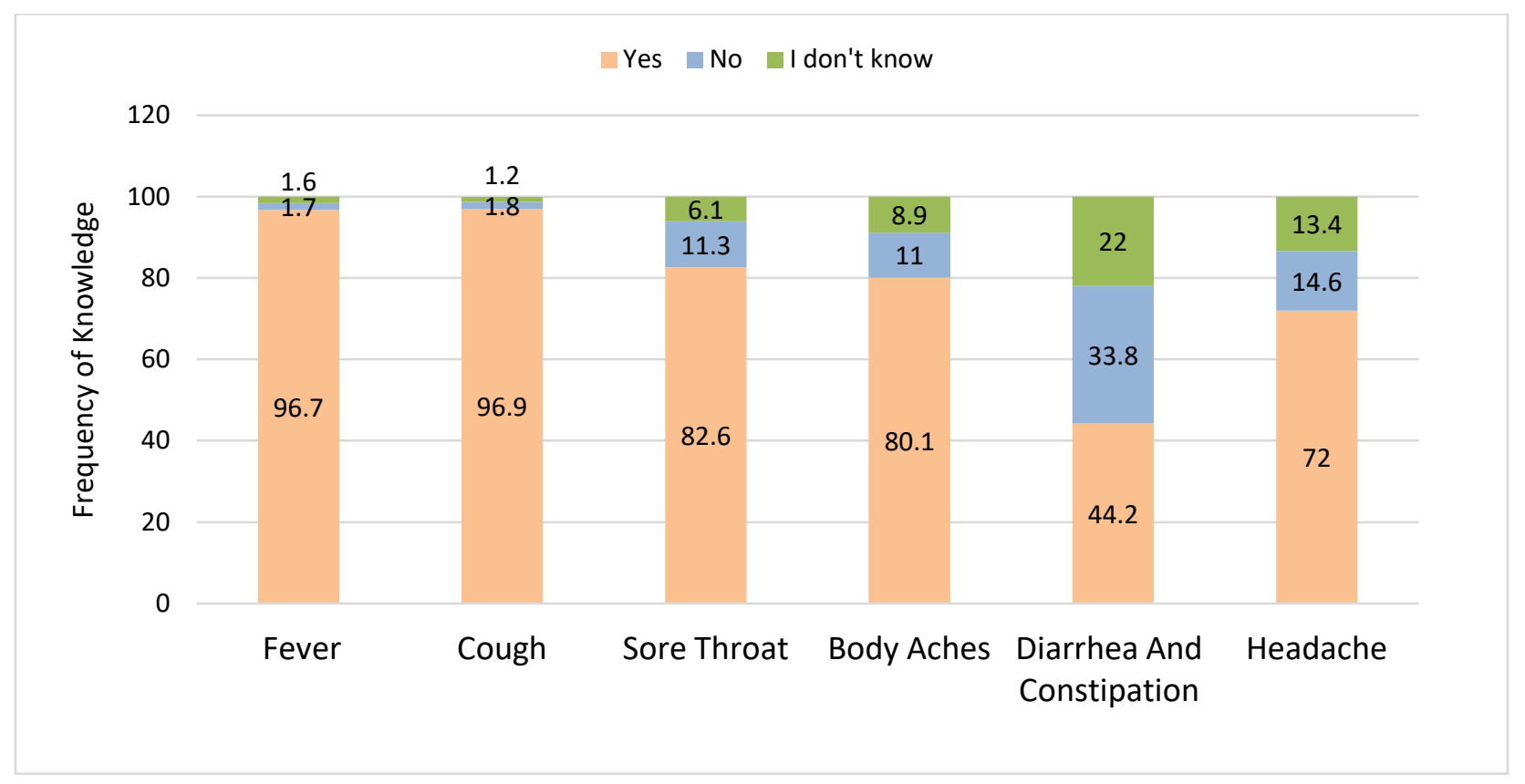

Figure 1: Descriptive Frequency of Knowledge against Novel Coronavirus (COVID-19) Among the Jahrom city people $88.6 \%, 90.6 \%$ and $96.3 \%$ of the subjects mentioned direct transmission during coughing and touching of infected surfaces and contact with infected persons (shaking hands, rubies, hugging). The majority of subjects though that older people (89.4\%), people with weakened immune systems (91\%) and having the underlying disease (cancer, chronic respiratory disease, diabetes, kidney failure) (94.1\%) are in high-risk groups (Figure 2).

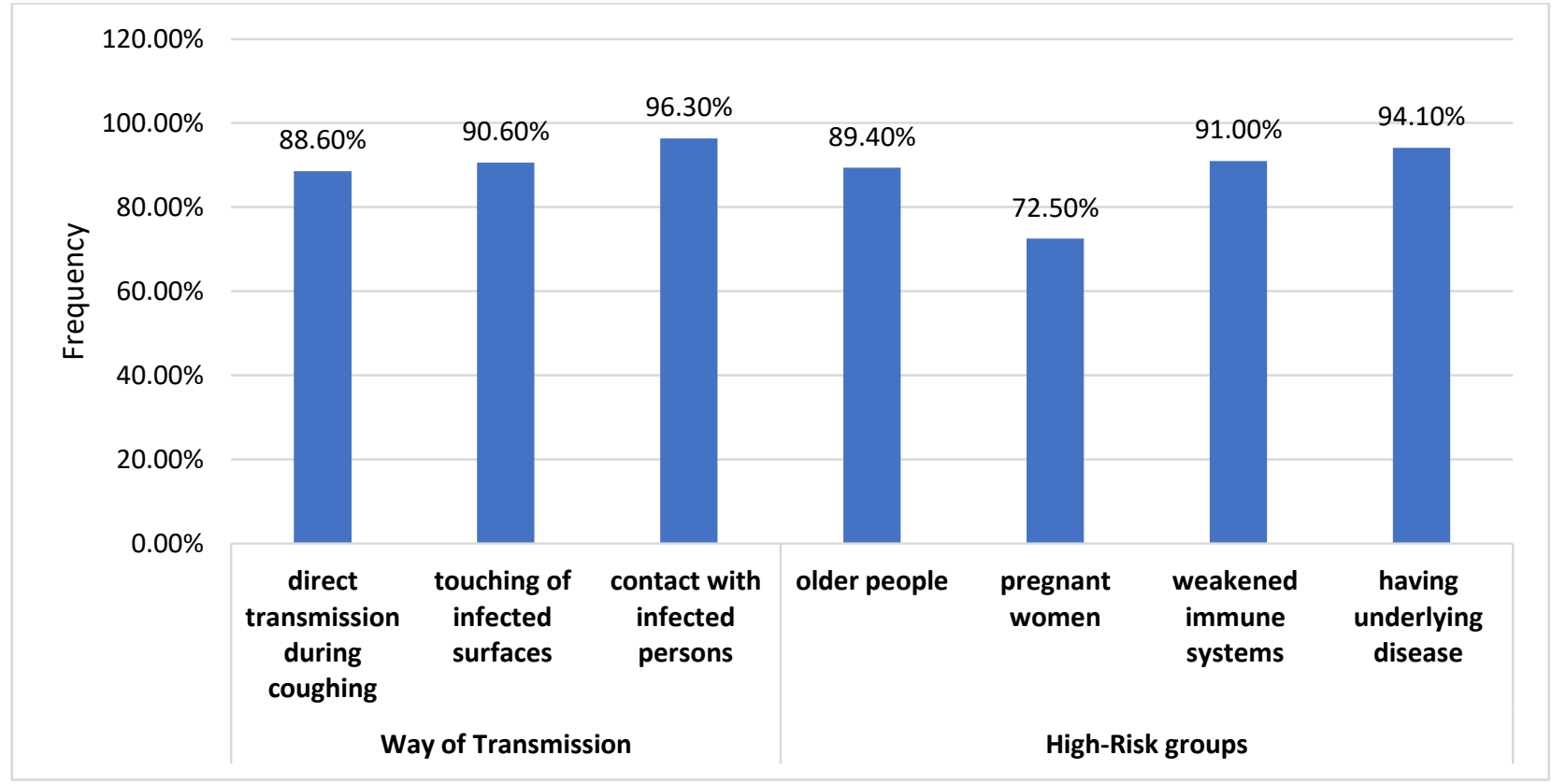

Figure 2: Descriptive Frequency of high-risk groups and way of transmission ways against COVID-19 
Knowledge, Attitude and practice against the 2019 Novel Coronavirus(COVID-19) Among the Jahrom city people:

\section{A Cross-Sectional Study}

The mean score of knowledge, attitude, and practice of people in Jahrom city was above average and $68.14,78.73,79.68 \%$ (out of $100 \%$ ), respectively. Trust to the media (audio-visual and virtual media, magazines and publications) was moderate (49.18\%).

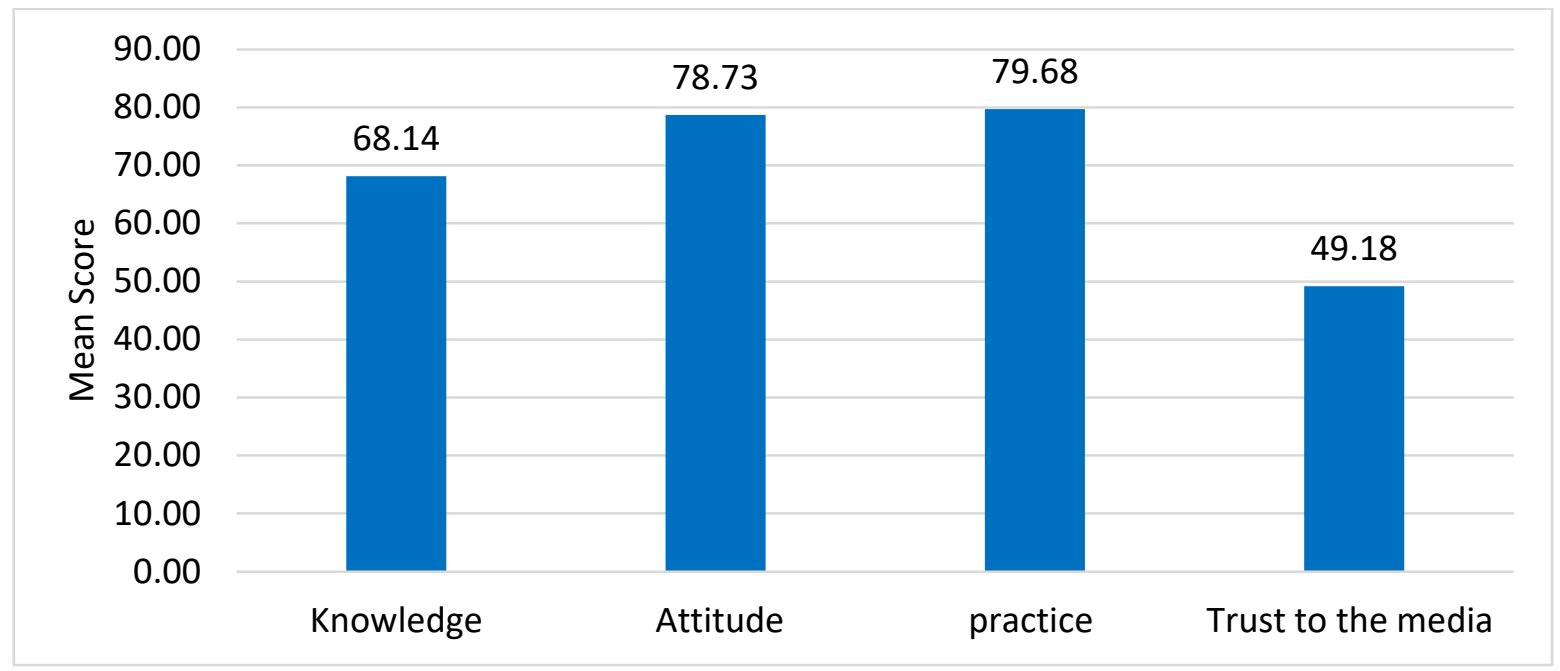

Figure 3: The mean score of Knowledge, Attitude, Practice and Trust to the media of people in Jahrom city

$60.8 \%$ of the survey participants believed that awareness of COVID-19 is not enough in society and only $3.6 \%$ of them believed that death was the result of all cases of COVID-19 infection. $61.3 \%$ believed that patients with COVID-19 can be cured. In other respects, people's attitudes toward COVID-19 were positive.

The practice of the majority of subjects in Jahrom was positive about COVID-19. They did not leave home in $94.1 \%$ of cases, avoid unnecessary travel in $99.2 \%$, avoid out of home foods in 97.5\%, and avoid handshaking in $99 \%$, no use of public transport in $96 \%$, doing hand washing in $98.9 \%$, considering more personal hygiene $98.5 \%$, use of disinfectant solutions in $96.6 \%$ of cases. $13.3 \%$ of people did not use a mask. $40.5 \%$ used masks only in crowded places, $41.4 \%$ in most places and $4.8 \%$ were always using it.

$24.8 \%$ of the study participants considered their risk of being infected to coronavirus to be high and only $35.8 \%$ as low.

Almost half of the study participants (52.1\%) were receiving most of their information from TV. $62.3 \%$ of them were receiving most information from social networks and the Internet. The amount of information received from scientific journal articles and by physicians and nurses was low (Figure 5). Trust in information obtained from physicians and nurses (67.8\%) and journals and scientific articles (16.7\%) were higher than other sources (Chart 5).

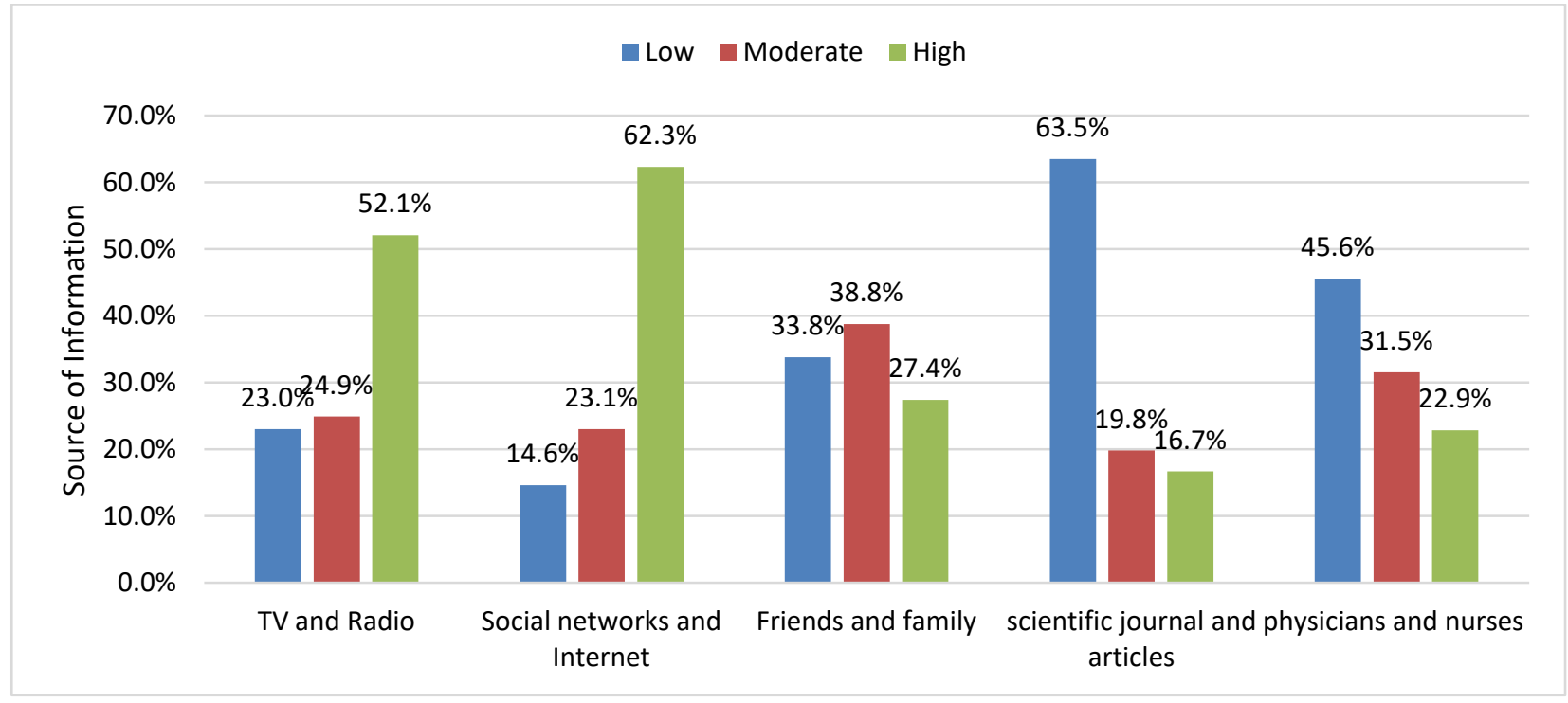

Figure 4: Descriptive Frequency of Source of Information of COVID-19 from the perspective of the people of Jahrom 
Knowledge, Attitude and practice against the 2019 Novel Coronavirus(COVID-19) Among the Jahrom city people:

\section{A Cross-Sectional Study}

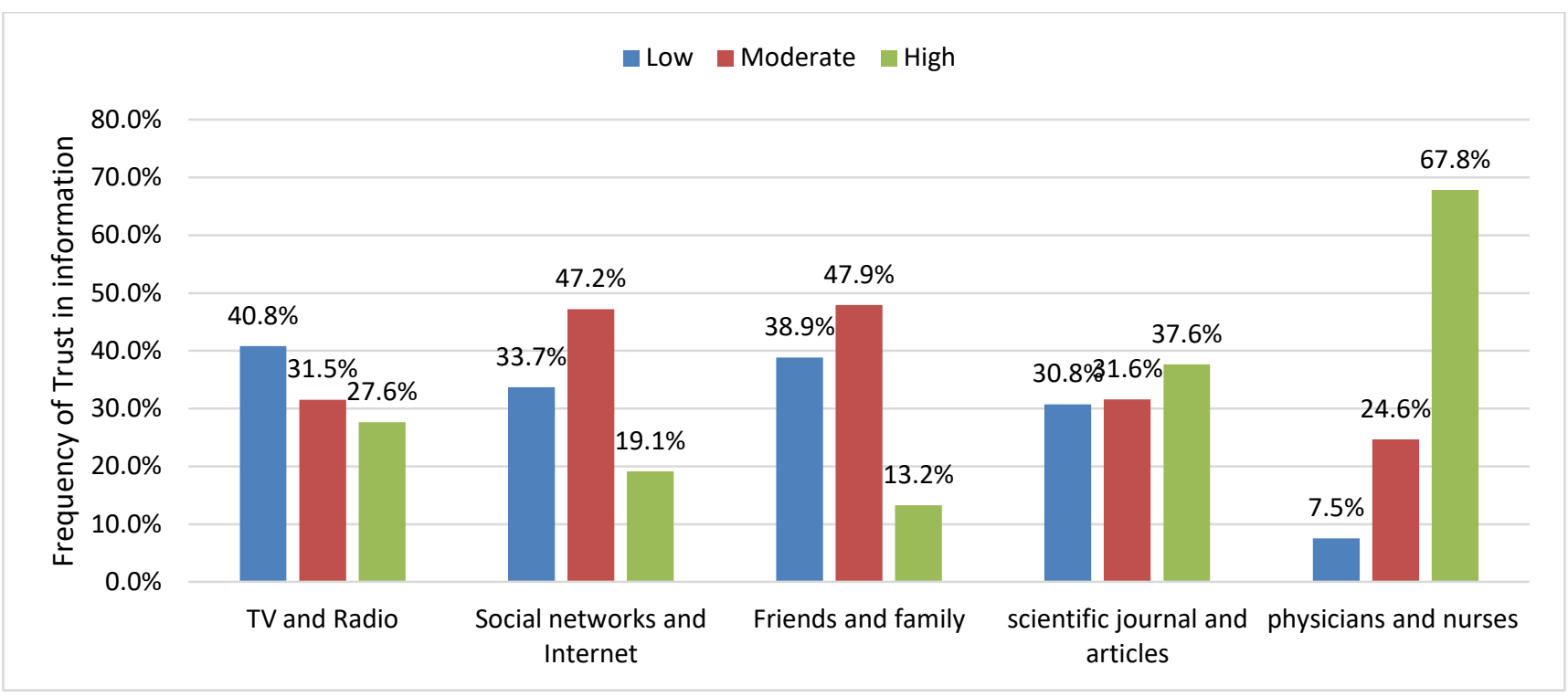

Figure 5: Descriptive Frequency of Trust in the information of COVID-19 from the perspective of the people of Jahrom

Multiple Linear regression test was done including demographic variables such as gender, age, education, marital status, and the number of households as predictor variables; no significant difference for mean awareness. It showed that these measures reduced the awareness of coronaviruses by $11.2 \%$ of the variance $(p=0.001, F=28.057)$. The effect of gender, age, level of education, marital status, and the number of households was significant for coronavirus awareness. The effect of male gender and number of inverted households and age, educational level and marital status were observed. Also among demographic variables, gender, age, and education level, as the variable with no power, there is no significant value for attitudes toward coronary viruses. It showed that these measures reduced the awareness of attitudinal awareness by 2.9 percent of variance ( $p$ $=0.001, F=6.78$ ). The effect of Gender reverses the effects of age and education were directly observed. Also, among demographic variables, the only gender has significant power for coronary artery disease. It showed that the yeast inhibited $1.5 \%$ of the variance of coronavirus variance $(F=3.30, p=0.002)$. The opposite sex effect was observed.

Table 3. Predicting people's knowledge, attitude and practice of coronavirus based on demographic variables by Multiple Linear regression

\begin{tabular}{|r|l|l|r|l|l|l|l|r|r|}
\hline variable & \multicolumn{4}{r|}{ practice } & \multicolumn{3}{r|}{ Attitude } & \multicolumn{3}{r|}{ Knowledge } \\
\hline & $\mathrm{p}$-value & $\mathrm{T}$ & $\boldsymbol{\beta}$ & $\mathrm{p}$-value & $\mathrm{T}$ & $\boldsymbol{\beta}$ & $\mathrm{p}$-value & $\mathrm{T}$ & $\boldsymbol{\beta}$ \\
\hline sex & 0.062 & 1.865 & 0.056 & $<0.001$ & 3.253 & 0.096 & $<0.001$ & 4.729 & 0.134 \\
\hline age & 0.33 & 0.968 & 0.026 & $<0.001$ & 4.400 & 0.116 & $<0.001$ & 9.618 & 0.242 \\
\hline $\begin{array}{r}\text { Education } \\
\text { level }\end{array}$ & 0.515 & - & - & 0.870 & - & - & 0.782 & 0.276 & 0.007 \\
\hline occupation & 0.223 & 0.651 & 0.018 & & 0.163 & 0.005 & & & \\
\hline $\begin{array}{r}\text { Marital } \\
\text { status }\end{array}$ & 0.701 & 0.384 & 0.010 & 0.952 & 0.060 & 0.002 & .897 & 0.130 & 0.003 \\
\hline housing & 0.948 & - & - & 0.802 & - & - & 0.0120 & -2.520 & -0.063 \\
& & 0.065 & 0.002 & & 0.251 & 0.007 & & & \\
\hline
\end{tabular}

The results of statistical analysis in Table S1 showed that knowledge, attitude, and practice of women in Jahrom city about COVID-19 was higher than men. As the age and level of education increase, the average knowledge and attitude of people increased. People aged 18 to 30 years and those with less than a high school diploma had the lowest knowledge and attitude. Among occupations, health professionals had the highest knowledge and attitude and workers and students had the lowest. The results showed that there was a significant difference between the level of knowledge and attitude of people according to gender, age, education, job and marital status ( $p$-value $<0.001$ ). Finally, there was a significant difference only between the practice in terms of gender ( $p$-value $<0.001$ ). 
Knowledge, Attitude and practice against the 2019 Novel Coronavirus(COVID-19) Among the Jahrom city people:

\section{A Cross-Sectional Study}

\section{DISCUSSION:}

Prevention of the spread of COVID-19 has become one of the major goals of the health system in the world. Unfortunately, in most developing countries, because of the lack of reliable and available information, there is disagreement about the underlying causes of the epidemic and how it changes over time, or among the different communities at greatest risk. However, this information is crucial to making strategic decisions about COVID-19 prevention. But the important point is that unfortunately, the outbreak is spreading through contact with asymptomatic carriers. Therefore, defining comprehensive and targeted approaches to preventing this disease is needed for society.

People are receiving a huge volume of information because of wide access to different news sources and social media, and in the Coronavirus outbreak, people's attention is drawn to inaccurate and sometimes wrong information. Inaccurate information from different sources can have serious consequences for society (9).

Based on the results of this study, the majority of respondents cited internet social networks as their main source of information about COVID-19. Social networks appear to be better than the mass media, including television, in implementing COVID-19 disease prevention training programs. However, public confidence in the news on social media and television has declined. In contrast, only $27.4 \%$ of respondents reported having received information about COVID-19 from their families, which unfortunately indicates that there is very little training on COVID-19 and its prevention among Iranian families. All people in the community should be encouraged to implement COVID-19 disease prevention programs and this could have a potential role in limiting the emergency status of COVID-19 in Iran.

In terms of demographic variables, our study showed that men and young people had poorer knowledge, attitude, and practice. While meeting the urgent needs of families and accessing the outdoors is often done by men and young people, poorer knowledge and attitude and practice can increase the prevalence of the disease. As in the study of Chen et al. (10), men were more susceptible to infection. In their study older men were more reported to be infected; while in our study, young people were less aware of the disease. But most asymptomatic cases happen in young people (11). Similar to our study, in the study of Srichan et al. (12), which examined the knowledge, attitude, and practices of the Thai people towards COVID-19, women had better knowledge and practice than men. Also in their study, higher literacy level was correlated with better knowledge and practice of people, which was also found in our study.

Given the high level of awareness, attitude, and practice of women toward men, it may be related to their greater interest in life and their greater motivation to learn about it. Perhaps women's interest in public relations and their curiosity may play a role. As well as broadcasting and mass media is one of the sources of information about this issue and women spend more time at home than men and have more time to get information from them, their awareness is higher than men.

In China shortly after the COVID-19 virus epidemic, the researchers sought to examine the level of influence of various health organizations' warnings and safeguards against the virus on community members, then concluded that people's knowledge has a positive association with their attention to health warnings. Zhang and his colleagues sought to test the level of knowledge and awareness of Chinese residents about coronavirus and its symptoms and complications. In this study, residents 'awareness of the various areas of the disease was assessed by a questionnaire, which included clinical symptoms, how to prevent the virus and residents' efficacy in dealing with COVID-19 patients. The study concluded that health education programs aimed at improving COVID-19 knowledge were useful in preventing and reducing the incidence of the disease. The study also found that high levels of literacy and residents' knowledge of the disease and its consequences and symptoms are crucial to maintaining optimistic attitudes and appropriate ways of dealing with the disease. However, due to the small number of studies in this field and the small number of people enrolled in their study, the results of their study cannot be assigned to the whole population and further studies are needed, as well as our study.

\section{CONCLUSION:}

The findings of this study provided important and essential information about the level of knowledge, attitude, and practices of the citizens of Jahrom that are experiencing a widespread outbreak. Our study population had moderately favorable knowledge and positive attitudes toward COVID-19. At the same time, the study population is not well aware and suffers from misconceptions about COVID-19. Therefore, it is necessary to implement health education programs aimed at covering all citizens, especially in the younger age groups.

ETHICAL CODE:

Approval ID: IR.JUMS.REC.1398.122

Evaluated by: Jahrom University of Medical Sciences 
Knowledge, Attitude and practice against the 2019 Novel Coronavirus(COVID-19) Among the Jahrom city people: A Cross-Sectional Study

\section{ACKNOWLEDGEMENT:}

We would like to thank the Clinical Research Development Unit of Peymanieh Educational and Research and Therapeutic Center of Jahrom University of Medical Sciences for providing facilities to this work.

\section{AUTHORS CONTRIBUTIONS:}

All the authors met the criteria of authorship based on the recommendations of the international Committee of Medical Journal EDITORS.

\section{CONFLICT OF INTEREST:}

There are no conflicts of interest in this study

\section{SUPPLEMENTARY:}

Supplementary Table 1. Score percentage of Knowledge, Attitude, and Practice in comparison of demographic characteristics

\begin{tabular}{|c|c|c|c|c|c|c|c|}
\hline & & Knowledge & $p$-value & Attitude & $p$-value & Practice & p-value \\
\hline sex & $\begin{array}{c}\text { female } \\
\text { male }\end{array}$ & $\begin{array}{l}68.89 \pm 8.43 \\
67.13 \pm 8.66\end{array}$ & $<0.001$ & $\begin{array}{c}78.87 \pm 9.71 \\
78.54 \pm 10.48\end{array}$ & $<0.001$ & $\begin{array}{l}80.59 \pm 10.80 \\
78.44 \pm 12.16\end{array}$ & 0.026 \\
\hline age & $\begin{array}{l}18-30 \text { years } \\
31-40 \text { years } \\
41-50 \text { years } \\
51-60 \text { years }\end{array}$ & $\begin{array}{l}66.11 \pm 8.93 \\
68.53 \pm 8.20 \\
69.81 \pm 8.56 \\
69.92 \pm 7.62\end{array}$ & <0.001 & $\begin{array}{c}77.11 \pm 10.61 \\
79.12 \pm 9.76 \\
79.38 \pm 10.13 \\
81.09 \pm 8.33\end{array}$ & 0.005 & $\begin{array}{c}78.79 \pm 13.17 \\
79.73 \pm 10.85 \\
80.81 \pm 10.75 \\
80.20 \pm 8.67\end{array}$ & 0.196 \\
\hline $\begin{array}{l}\text { Education } \\
\text { al level }\end{array}$ & $\begin{array}{c}\text { Lower than diploma } \\
\text { Diploma } \\
\text { associate } \\
\text { Bachelor } \\
\text { Higher }\end{array}$ & $\begin{array}{c}63.48 \pm 10.28 \\
66.91 \pm 8.63 \\
67.47 \pm 8.44 \\
69.65 \pm 7.39 \\
70.67 \pm 7.85\end{array}$ & <0.001 & $\begin{array}{c}76.35 \pm 12.32 \\
77.96 \pm 10.53 \\
78.33 \pm 8.89 \\
79.63 \pm 9.55 \\
79.96 \pm 8.59\end{array}$ & $<0.001$ & $\begin{array}{c}78.76 \pm 14.29 \\
79.78 \pm 12.33 \\
78.71 \pm 10.80 \\
80.24 \pm 9.96 \\
79.52 \pm 11.14\end{array}$ & 0.587 \\
\hline $\begin{array}{c}\text { occupatio } \\
n\end{array}$ & $\begin{array}{c}\text { Unemployed } \\
\text { student } \\
\text { Self-employed } \\
\text { Health worker } \\
\text { employee } \\
\text { jobholder } \\
\text { others }\end{array}$ & $\begin{array}{l}68.03 \pm 8.30 \\
63.78 \pm 8.91 \\
66.54 \pm 9.08 \\
72.42 \pm 6.41 \\
63.26 \pm 8.92 \\
69.99 \pm 7.70 \\
68.98 \pm 8.24\end{array}$ & k0.001 & $\begin{array}{c}78.05 \pm 10.28 \\
76.32 \pm 10.70 \\
78.32 \pm 10.95 \\
81.07 \pm 8.41 \\
77.70 \pm 10.39 \\
80.07 \pm 9.02 \\
78.64 \pm 9.89\end{array}$ & $<0.001$ & $\begin{array}{c}81.03 \pm 11.02 \\
76.98 \pm 16.17 \\
79.30 \pm 12.22 \\
79.26 \pm 10.08 \\
78.07 \pm 11.71 \\
79.89 \pm 10.35 \\
80.30 \pm 9.18\end{array}$ & 0.164 \\
\hline $\begin{array}{l}\text { Marital } \\
\text { status }\end{array}$ & $\begin{array}{c}\text { single } \\
\text { married } \\
\text { other }\end{array}$ & $\begin{array}{l}65.53 \pm 9.32 \\
68.99 \pm 8.16 \\
69.12 \pm 6.37\end{array}$ & $<0.001$ & $\begin{array}{c}76.94 \pm 10.34 \\
79.30 \pm 9.90 \\
79.49 \pm 9.47\end{array}$ & $<0.001$ & $\begin{array}{c}78.09 \pm 13.49 \\
80.24 \pm 10.66 \\
78.38 \pm 9.87\end{array}$ & 0.065 \\
\hline housing & $\begin{array}{l}\text { apartment } \\
\text { Townhouse }\end{array}$ & $\begin{array}{l}68.28 \pm 8.24 \\
68.06 \pm 8.77\end{array}$ & 0.807 & $\begin{array}{c}78.70 \pm 9.73 \\
78.74 \pm 10.24\end{array}$ & 0.514 & $\begin{array}{l}79.53 \pm 11.87 \\
79.77 \pm 11.18\end{array}$ & 0.194 \\
\hline
\end{tabular}

